\title{
High-resolution images and drone-based LiDAR reveal striking patterns of vegetation gaps in a wooded spinifex grassland of Western Australia
}

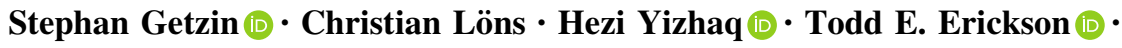 \\ Miriam Muñoz-Rojas $(\mathbb{D} \cdot$ Andreas Huth $\cdot$ Kerstin Wiegand $(\mathbb{D}$
}

Received: 23 June 2021 / Accepted: 19 October 2021/Published online: 3 November 2021

(C) The Author(s) 2021

\begin{abstract}
Context Vegetation patterns in hummock grasslands of Australia's arid interior can be very complex. Additionally, the grasslands are interspersed with variable amounts of trees and shrubs.

Objectives To better understand the spatial arrangement of this vegetation structure, and in particular the unvegetated bare-soil gaps, we analyzed the scaledependent patterns of gaps, trees, and shrubs.

Methods We focused on two size categories of grassland gaps, large gaps $\geq 4 \mathrm{~m}^{2}$ known as fairy circles (FCs) and small gaps 1 to $<4 \mathrm{~m}^{2}$, and on trees and shrubs. We mapped four $200 \mathrm{~m} \times 200 \mathrm{~m}$ study plots located east of the town of Newman in Western
\end{abstract}

Supplementary Information The online version contains supplementary material available at https://doi.org/10.1007/ s10980-021-01358-9.

S. Getzin $(\bowtie) \cdot$ C. Löns $\cdot$ K. Wiegand

University of Goettingen, Goettingen, Germany

e-mail: stephan.getzin@uni-goettingen.de

S. Getzin · A. Huth

Helmholtz Centre for Environmental Research - UFZ,

Leipzig, Germany

H. Yizhaq

Ben-Gurion University of the Negev, Sede Boqer, Israel

T. E. Erickson · M. Muñoz-Rojas

The University of Western Australia, Crawley, Australia
Australia, using drone-based aerial images and LiDAR. The RGB images were converted into binary images and the gaps and woody plants were automatically segmented. The spatial patterns of the four vegetation components were analyzed, as well as the shape properties of the vegetation gaps.

Results The most striking result was that small gaps appeared consistently at about $5 \mathrm{~m}$ distance away from the FCs, which are known as the most waterdepleted locations in the grassland. The FCs were also rounder than the small gaps and this symmetry underlines their function as an extra source of water for the surrounding matrix vegetation. Trees and shrubs had spatial patterns that were unrelated to FCs, which likely results from their water uptake in deeper sub-soil layers.

\author{
T. E. Erickson · M. Muñoz-Rojas \\ Kings Park Science, Department of Biodiversity, \\ Conservation and Attractions, Perth, Australia \\ M. Muñoz-Rojas \\ Centre for Ecosystem Science, UNSW Sydney, Sydney, \\ Australia
}


Conclusions The consistent distance of small gaps to FCs is further support that the Australian fairy circles are a self-organized vegetation pattern that results from ecohydrological feedbacks.

Keywords Australia - Fairy circles - Gap shape complexity index $\cdot$ LiDAR $\cdot$ Triodia $\cdot \mathrm{UAV}$

\section{Introduction}

Grassland gaps in arid ecosystems are common throughout the world. Probably the most famous grassland gaps are the so-called fairy circles. These fairy circles (FCs) are relatively large and round vegetation gaps that occur in a small area of Western Australia and also along the Namib Desert in southwestern Africa. FCs in Australia have mean diameters of four meters and large FCs can even exceed $7 \mathrm{~m}$ (Fig. 1a, Getzin et al. 2016, 2021a). In Namibia their diameters range mostly between four and ten meters (van Rooyen et al. 2004) with some "mega circles" exceeding $20 \mathrm{~m}$ (Getzin and Yizhaq 2019). One important aspect that characterizes the FCs is their unique ability to form so-called "spatially periodic" patterns, where the six nearest neighbors around any focal FC have approximately the same distances to the focal FC. Such FC distributions are a special form of a regular pattern with an extraordinary degree of overdispersion, and they appear so striking to the observer because of their strictly geometric spatial ordering (Getzin et al. 2019a).

Periodic vegetation patterns are an inherent characteristic of many arid ecosystems where the spatial periodicity results from biomass-water feedbacks and self-organization of plants that strongly compete for water (Deblauwe et al. 2008; Maestre et al. 2021). A typical example from Australia are the mulga trees that grow in banded patterns along hillslopes. The periodic distances between the bands are caused by interacting processes of run-off erosion and positive feedback with vegetation growth, resulting from better infiltrability under vegetated patches (Ludwig et al. 2005). While the individual mulga bands may not be physically connected, it is the hydrological flow of material that leads to functional connectivity of the vegetation (Okin et al. 2015).
Fig. 1 Example of a typical round Australian fairy circle in the plot L2 (Getzin et al. 2019b). The scale in the image is $50 \mathrm{~cm}$ long (a). In the background of the FC, a Eucalypt tree can be seen to the left. Example of a small gap in the plot L2 (b). Those small gaps form on soft sand, as the excavations revealed. Drone-based aerial image of the plot FC-C5 (c). The plot is $200 \mathrm{~m} \times 200 \mathrm{~m}$ and it contains FCs, small gaps, scattered trees, and shrubs. Conversion of the RGB orthophoto into a binary image with automatically delineated FCs and small gaps, using ImageJ software (d). Drone-based LiDAR was used to map the 3D-point clouds of the woody vegetation (e). Shown here is an example of the distribution of trees and shrubs in plot FC-C5, where red color indicates the highest parts of the vegetation. The inset in (e) shows the Microdrone md4-1000 with laser scanner and base station

Fairy circles in Australia have been compared to plant rings (Ross and Moles 2021) but it is important to note that the latter type of Triodia rings strongly differ from true FC grassland gaps which are "holes" in a more or less continuous vegetation matrix (Getzin et al. 2016, their Fig. 2). Grass rings are globally common in arid ecosystems, for example, in North America (Ravi et al. 2008). However, rings are local phenomena that are mostly disordered and that lack a spatial periodicity in the landscape-scale distribution. Rings are therefore not directly comparable to fairy circles, except for the fact that they are circular and that hydrological or aeolian processes may be involved in their formation.

Generally, FCs are not ordinary gaps such as common termite- or ant-induced holes in the vegetation but they differ from those in several important characteristics. For example, Namibian FCs do not show an obvious correlation with termite or ant nests in the gap centers (Tschinkel 2010, 2012; Ravi et al. 2017), which is a common feature of all insectinduced vegetation gaps. In contrast to common vegetation gaps induced by harvester termites (Watson et al. 1973, Noble et al. 1989), excavations of the Australian FCs revealed no termite causation and the spatial properties such as the sizes and patterns of the two types of gaps differed significantly (Getzin et al. 2019b). Another important characteristic of FCs is that they are strongly confined to a narrow climatic envelope. In Namibia, FCs occur only along a narrow corridor east of the Namib Desert where mean annual precipitation (MAP) ranges from 50 to $150 \mathrm{~mm}$ (van Rooyen et al. 2004). In the Pilbara of Western Australia, the FCs occur only in a small area east of 

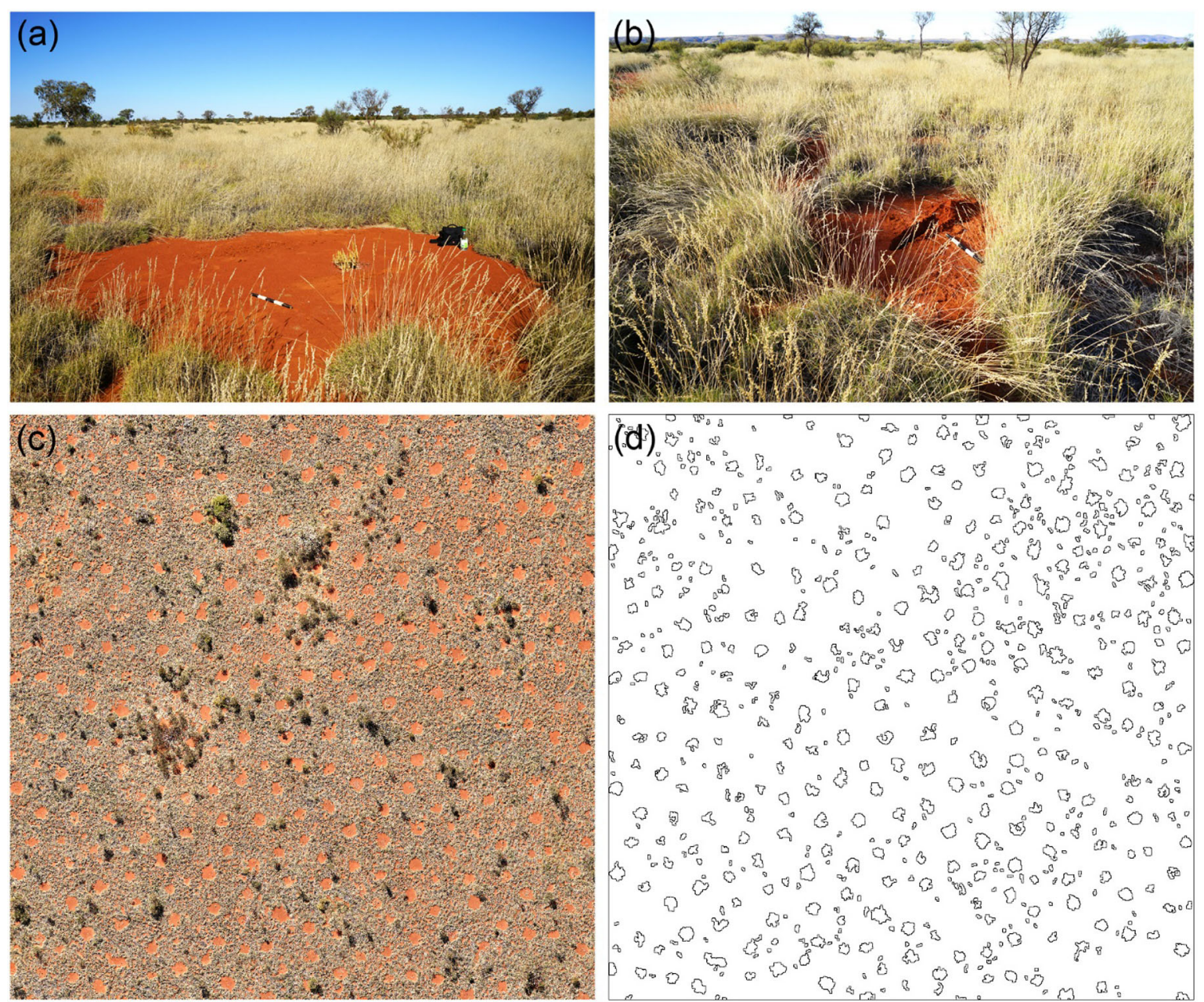

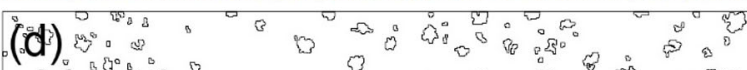

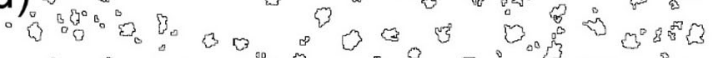

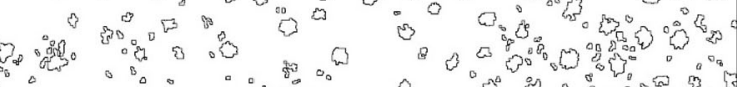

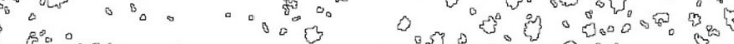
80000
30

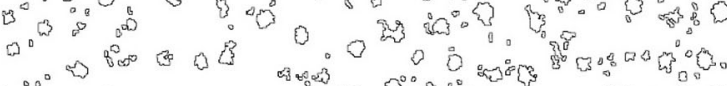

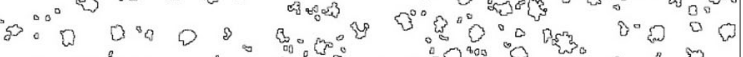

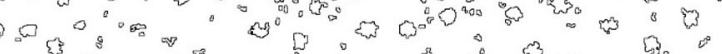

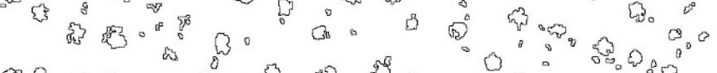

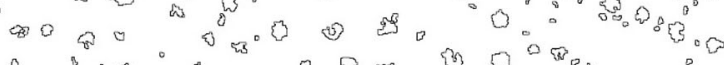

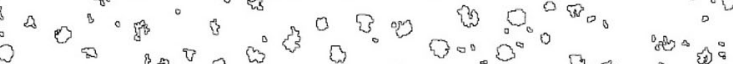

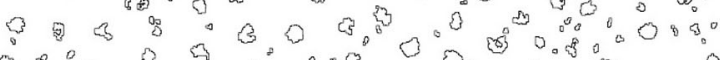

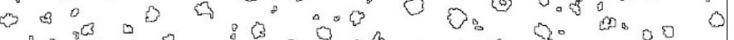

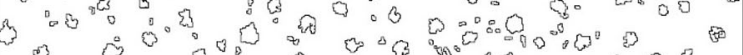

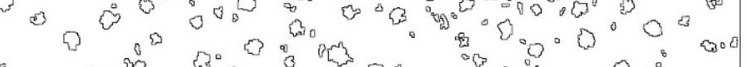

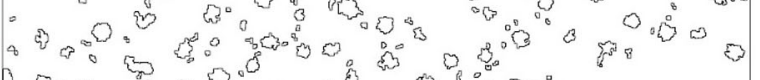

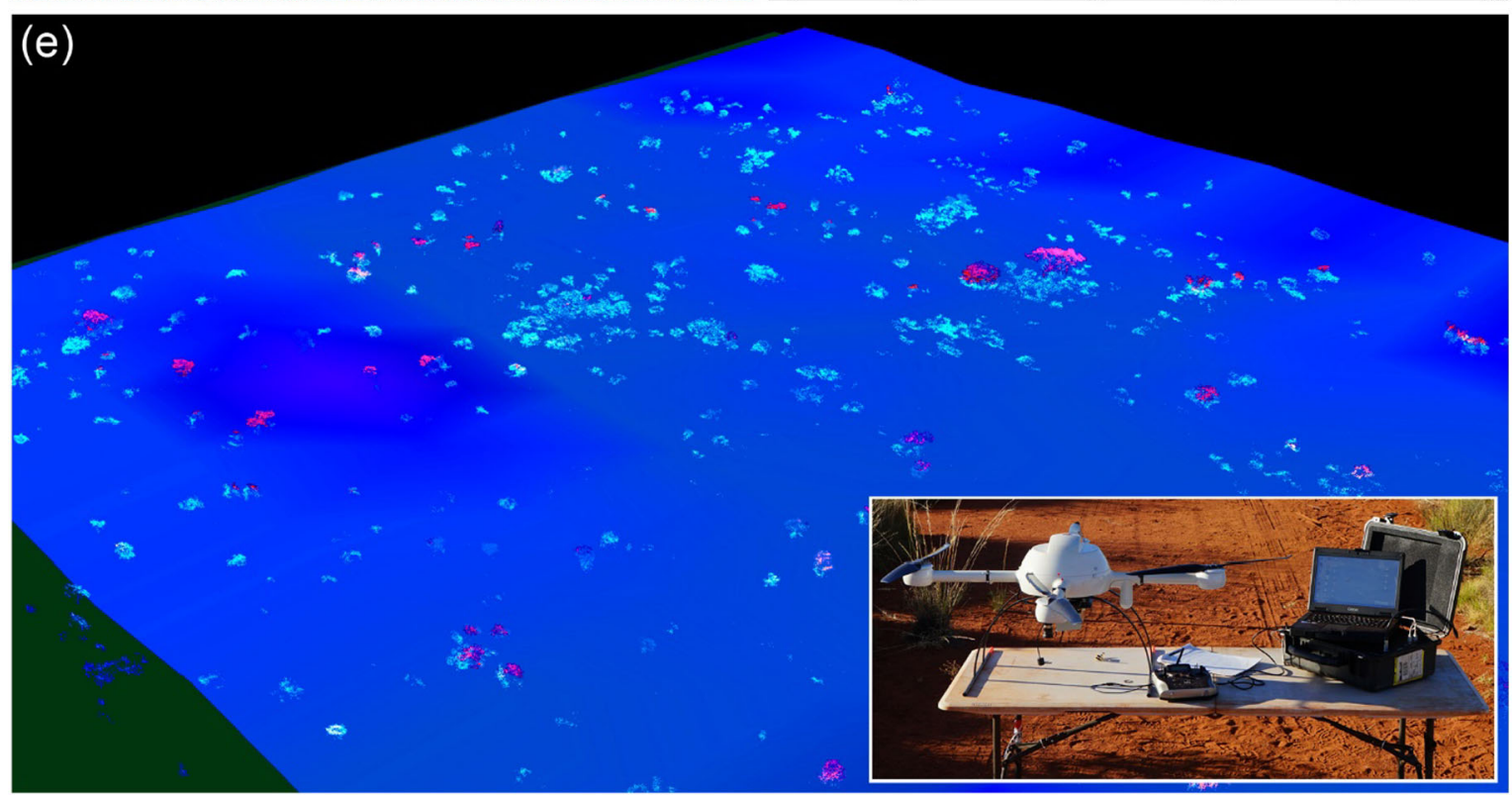




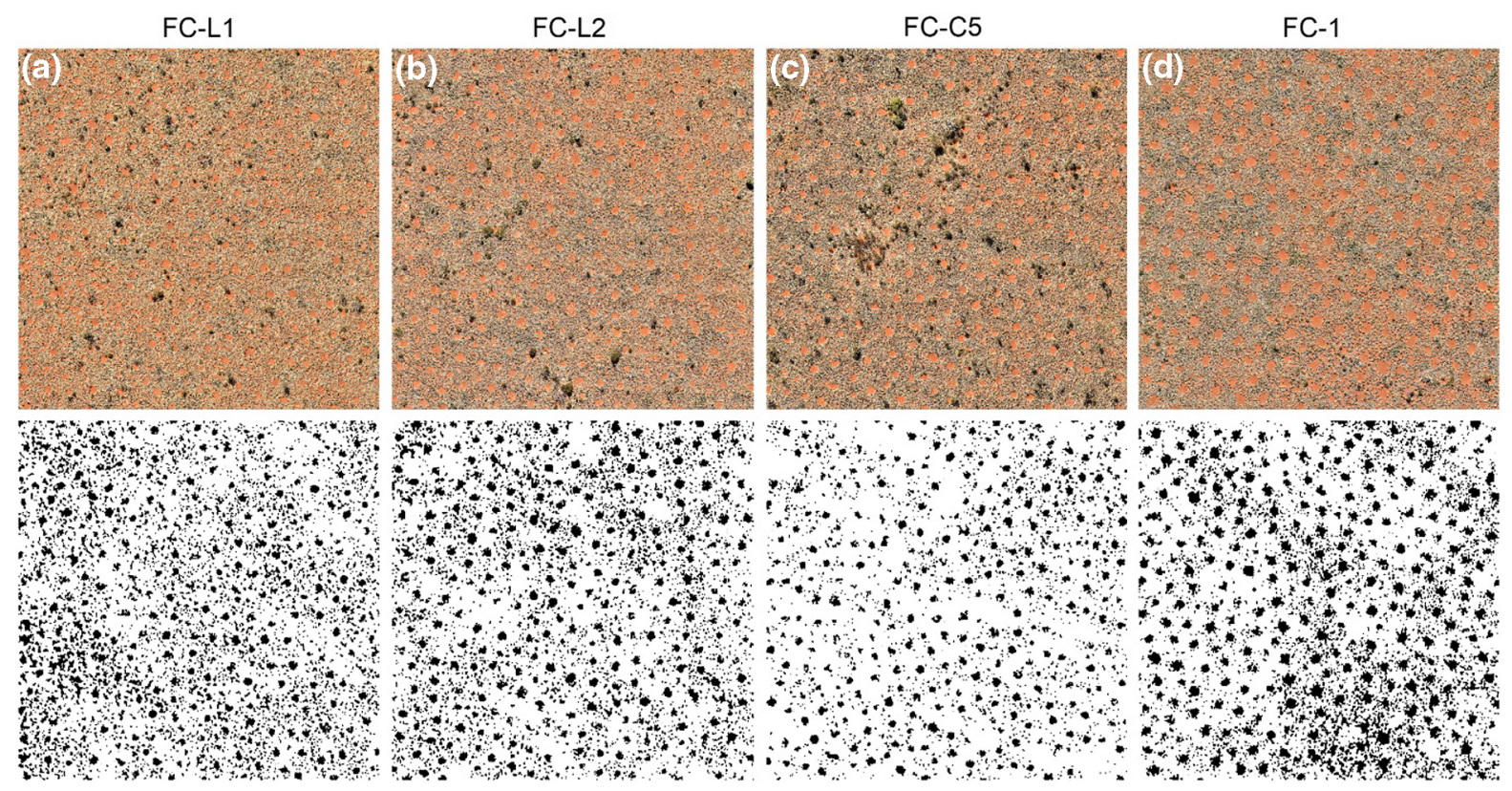

Fig. 2 The four drone-mapped $200 \mathrm{~m} \times 200 \mathrm{~m}$ plots are shown with RGB images (a-d) and the raw conversion into binary images (below)

the town of Newman, where MAP is $330 \mathrm{~mm}$ but annual evaporation is $3200-3400 \mathrm{~mm}$, hence in both countries FCs prevail in arid systems with an aridity index $<0.2$ (Getzin et al. 2016). This is in contrast to insect-induced grassland gaps occurring over wide climatic gradients in North America (Nicolai et al. 2010; Dibner et al. 2015), Namibia (Turner et al. 2006) or Australia (Watson et al. 1973; Noble et al. 1989; Abensperg-Traun and Perry 1998) because the active removal of vegetation by termites or ants or the formation of a termite pavement results always in a vegetation gap, irrespective of the climatic conditions. For these above-mentioned reasons, it has been suggested long ago that these special vegetation gaps of the FCs are most likely related to strong competition for limited resources such as soil water and nutrients (van Rooyen et al. 2004).

For the Australian FCs, it has recently been demonstrated with soil analyses and mathematical modelling, as well as with drone-based assessments of plant vitality, that these vegetation gaps result from ecohydrological feedbacks of the Triodia basedowii grasses that dominate the system (Getzin et al. 2016, 2021a). Driven by the region's climatically harsh conditions, these plants act as 'ecosystem engineers' because they modify the abiotic environment by redistributing the water resources (Getzin et al. 2021a), which helps to better cope with the hostile abiotic environment. After rainfall, the FCs with their strongly impermeable clay crusts function as an extra source of water for the surrounding matrix vegetation and the most vital grass individuals assemble themselves according to geometric rules around the FCs. These self-organized grassland gaps are therefore a prime example of an emergent vegetation pattern where plant-competitive interactions at lower levels of organization lead to higher level structures (Newman et al. 2019). The landscapescale patterns of mature FCs with diameters ranging from 2 to $7 \mathrm{~m}$ are best identified on remotely sensed satellite or aerial imagery, while accurate detection of smaller gaps requires higher resolutions, such as that obtained from drone imagery. So far, the mature fairy circles of Australia and their ecohydrological feedbacks have been investigated in great detail (Getzin et al. 2016, 2019b, 2021a) but the role and spatial arrangement of small gaps with sizes of 1 to $<4 \mathrm{~m}^{2}$ is still unexplored. So far, preliminary investigations of these relatively small gaps (Fig. 1b) revealed merely that such immature gaps developed on soft sand without any evidence of termite activity (Getzin et al. 2019b). 
Generally, since many processes may potentially contribute to or affect the formation of FCs, it is important to study such emerging patterns in as much detail as possible. A multi-criteria assessment of such landscape structures is therefore desirable in order to understand the full picture of the spatial dynamics that govern the emergence of patterns. For example, it is not yet known whether there is a scale-dependent relationship between the small gaps and the mature FCs or between the woody plants and the mature FCs. Demonstrating that such systematic relationships do or do not exist may help to further our understanding of the growth patterns of vegetation components, or may rule out unlikely hypotheses about the cause of the FCs if such spatial relationships do not exist.

Specifically, the spatial pattern of small gaps relative to the pattern of larger FCs has never been investigated. While the pattern of the FCs is spatially periodic, it is so far unclear if the small gaps with a size of only a few square meters are merely randomly distributed in the landscape or if they follow a statistical rule with a specific distance correlation to the FCs. Given that the FC patterning results from ecohydrological feedbacks (Getzin et al. 2021a), it can be expected that new FCs or small gaps would form at the most water-depleted locations in the matrix, which is about half-way the distance of two nearest-neighboring FCs. The mean nearest-neighbor distance between FCs in Australia is $10 \mathrm{~m}$ (Getzin et al. 2016), hence the most water-depleted locations should be, from a theoretical and mathematical point of view, $5 \mathrm{~m}$ away from the FC centers, where there is not enough water to sustain the growth of vegetation. However, this prediction has not yet been tested in the field.

Also, we would expect that the roundness of the gaps is greater in mature FCs while small gaps should be less round because they have only been formed recently, whereas the large FCs are expected to be long-lived, stable structures (Caviedes-Voullième and Hinz 2020; Getzin et al. 2021a). The larger FCs should have rounder shapes because they result from isotropic plant competition for water whereas new small gaps are more in a dynamic stage and likely more affected by noise (Fernandez-Oto et al. 2014). Small gaps that are bordered by very few large hummocks are also more affected by the shape and size of the few grass individuals making up the gap while this effect diminishes for large FCs. In comparison to other geometric shapes, a circle has the smallest circumference-to-area ratio. Since FCs are an additional water source for the surrounding grasses, a circular arrangement of plants enables each plant to maximize its percapita access to water. All this should result in rounder shapes of FCs in comparison to small gaps.

In this study, high-resolution aerial images were converted into binary images which allowed for an automatic feature extraction of all small vegetation gaps and FCs (Fig. 1c, d), enabling us to describe even the most complex shapes in an objective way.

Finally, the Australian FCs are interspersed with scattered eucalypt trees and shrubs. Such woody plants with their deep-reaching root systems compete for water in the deeper sub-soil layers whereas the grasses with their shallower roots compete primarily for water in the top-soil layer (Ward et al. 2013). This leads us to the assumption that the emergence and pattern of the fairy circles is unrelated to the pattern of the trees and shrubs. However, so far, the pattern of woody plants in a FC landscape has never been investigated for Australia. Therefore, we used drone-based LiDAR, enabling us to differentiate between trees and shrubs and to characterize the structural properties of the woody components (Fig. 1e).

Overall, we identify the following three hypotheses as research goals of this study:

1. Given that the Australian FCs are self-organized vegetation gaps that result from scale-dependent competition for water, small grassland gaps with a size of 1 to $<4 \mathrm{~m}^{2}$ should occur segregated from the larger FCs which supply the surrounding matrix vegetation with water.

The small gaps in the matrix are thus an expression for a shortage of water at "fixed" distances away from the FCs.

2. The spatially periodic pattern of the FCs results from symmetric competition for water.

Given that this scale-dependent competition for water is a long-lasting process and that many individual grasses make up the circle, the shape of the FCs should be rounder than that of the younger small gaps in the surroundings.

3. Fairy circles result from grass competition for water in the top-soil layer.

Given that trees and shrubs with their longer roots compete primarily for water in the deeper sub-soil layers, their spatial patterns should be unrelated to the FC patterns. 
Our research is important and relevant for arid ecosystems in a broader context because self-organized vegetation patterns are characterized by symmetry-breaking, hence by a uniform force that drives a uniform system out of equilibrium to induce spatially periodic patterns (Meron 2012). In this context, it is important to demonstrate empirically how the strictly geometric rules of pattern formation act on different hierarchical levels of ecosystem organization (Okin et al. 2015; Newman et al. 2019). This includes, for example, not only the large fairy-circle gaps, which are known to be stable over many decades (Tschinkel 2012), but also the small bare-soil gaps, which have received little attention so far. In particular, it is important to study the geometric arrangement of small bare-soil gaps, as this pattern may reveal subordinate levels of organization that can explain the periodic structuring of the fairy-circle landscape.

\section{Methods}

\section{Study area}

The Australian FCs can be found east of the mining town of Newman in north-west Western Australia (Fig. S1). They occur within a radius of $10 \mathrm{~km}$ east to south of the Ophthalmia Dam (Getzin et al. 2016, 2019b). Vegetation comprises hummock grasslands, tussock grasslands, sclerophyll shrublands, and woodlands with a tussock grass understorey (Van Vreeswyk et al. 2004). The local climate is arid with about $330 \mathrm{~mm}$ mean annual precipitation (MAP) and 3200-3400 $\mathrm{mm}$ annual evaporation (Australian Government Bureau of Meteorology 2018). Air temperatures in the summer months December and January can be very high with daily maxima exceeding 47 to $48{ }^{\circ} \mathrm{C}$ (Getzin et al. 2021a). Soil surface temperatures in the upper centimeter on bare ground in FCs can reach $75{ }^{\circ} \mathrm{C}$, and mechanical weathering in these harsh conditions leads to the formation of physical clay crusts with compacted and sealed surfaces, which largely hampers grass growth within the FCs (Getzin et al. 2016, 2019b). This landscape with FCs is very flat and the plains are sandy, comprising Red Kandosols, Red Ferrosols and Leptic Rudosols (Isbell 2002). These Triodia grasslands burn approximately every 15-30 years, destroying the entire grass vegetation (Levin et al. 2012; Muñoz-
Rojas et al. 2016). All FC locations are monospecifically dominated by the spinifex grass Triodia basedowii E. Pritz.

We studied the vegetation in four $200 \mathrm{~m} \times 200 \mathrm{~m}$ plots (Fig. S1) that have been drone-mapped and described in detail by Getzin et al. (2021a). At the time of the survey, the plots 'FC-L1', 'FC-L2' and 'FC-C5' did not burn for more than 15 years. Hence, they represent typical climax stages of long unburnt Triodia grasslands. The plot 'FC-1' had an estimated post-fire age of about 10 years. We did not analyze the fifth plot 'FC-C2' from the above study because its post-fire age was $<3$ years, thus it was unsuitable to investigate the very small gaps that may only be visible with time in the growing matrix vegetation. The plot FC-L1 was not as homogeneously covered with FCs as the other three plots because the plot had transitions to labyrinthine and irregularly shaped baresoil gaps. All four grassland plots contained scattered trees and shrubs in variable densities and included species such as Acacia aneura (commonly known as 'mulga'), A. pruinocarpa, A. tenuissima, Hakea chordophylla, Capparis spp., and various Eucalyptus species such as E. victrix. The primary goal of this study was to assess these trees and shrubs for their spatial structure within the FC area and therefore specific taxonomic mapping was not required. Based on our fieldwork experience, we classified the vegetation into three general height levels: Triodia grasses $\geq 1 \mathrm{~cm}$ to $<100 \mathrm{~cm}$, shrubs $\geq 100 \mathrm{~cm}$ to $<300 \mathrm{~cm}$, trees $\geq 300 \mathrm{~cm}$.

\section{Drone survey}

We undertook a drone (unmanned aerial vehicle, UAV) survey between the 7th and 25th of July 2017, where we mapped the four plots with a Microdrone md4-1000 quadcopter and an attached photo camera, as well as a laser scanner.

We used the 24-megapixel photo camera SONY NEX-7 and a flying altitude of $40 \mathrm{~m}$ above the ground to get an image resolution of $1 \mathrm{~cm} /$ pixel. The programmed flying speed was $3 \mathrm{~m} / \mathrm{s}$ and $420 \mathrm{RGB}$ images were taken with an $85 \%$ forward and $70 \%$ sideward overlap.

The Microdrone md4-1000 can carry a weight of $1 \mathrm{~kg}$ for a flight duration of about $25 \mathrm{~min}$. Hence, we installed a SICK LD-MRS (Multi-layer Range Scanner) laser scanner to map the woody vegetation with 
drone-based LiDAR (Fig. 1e). Such laser scanners provide accurate information on the height of vegetation and they outperform Structure-from-Motion (SfM) algorithms based on 2D-photos that are commonly used as a low-cost alternative (Wallace et al. 2016). The scanner received simultaneously echoes from four parallel layers and up to three returns per pulse. The laser point rate was approximately 19500 points/s with an infrared light wavelength of 895 to $915 \mathrm{~nm}$. Depending on the flying altitude, the type of vegetation, and the speed of flying, very high point densities can be achieved. In order to achieve a maximum data quality, we set the flying speed to $2 \mathrm{~m} /$ $\mathrm{s}$, which was fast enough to stabilize the drone while flying, but also slow enough to enable high point densities. The three plots FC-L1, FC-L2 and FC-1 were mapped at an altitude of $30 \mathrm{~m}$ above ground, and for testing higher point densities, the plot FC-C5 was flown at $20 \mathrm{~m}$ above ground. The resultant point densities ranged between 114 and 133 points $/ \mathrm{m}^{2}$ for the plots FC-L1, FC-L2 and FC-1, and 185 points $/ \mathrm{m}^{2}$ for the plot FC-C5. However, all point clouds were randomly thinned to 100 points $/ \mathrm{m}^{2}$. Given that this is still a very high point density far beyond generated point clouds typically produced by conventional airborne laser scanning, this standardized density enabled a direct LiDAR comparison of all four plots.

\section{Preparation of drone data}

The RGB photos were stitched together into georeferenced orthophotos (Fig. 2a-d) using OneButton software (version 5.1.0.57, www.icaros.us). Gap shapes and the distribution of bare soil in these hummock grasslands are usually very complex. Since the goal of this study was to analyze specifically the very small vegetation gaps with a size of only 1 to $<4 \mathrm{~m}^{2}$, only an automatic feature extraction enabled us to digitize and quantify such gaps in an objective manner. For this reason, we converted the RGB photos into binary images with a constant threshold grey level of 200 (Fig. 2) and tested several image resolutions (1, $10,20,50 \mathrm{~cm} /$ pixel) for finding the most reasonable gap extractions. We then used ImageJ software (version 1.52a, https://imagej.nih.gov/ij/) and the mode "Analyze Particles" to segment the individual gaps, deleting all unconnected or single pixels that did not jointly form a minimal size of $1 \mathrm{~m}^{2}$ based on the tested image resolution. It turned out that an image resolution of $20 \mathrm{~cm} /$ pixel represented the individual shape and distribution of small gaps and FCs in the best way (Fig. 1c, d). Finer resolutions resulted into shapes too complex for analyzing and more connected gaps, while a coarser resolution resulted in a loss of information. With the mode "Analyze Particles" we also obtained information on the $x, y$-coordinates of the gap centers, as well as the area $(A)$, perimeter $(P)$, and shape properties (e.g. roundness and shape complexity) of each gap.

Roundness of a gap is calculated as Roundness = $\frac{4 A}{\pi D^{2}}$ where $D$ is the length of the major axis. Roundness is the inverse of the Aspect Ratio $(A R=$ major axis length of approximate ellipse / minor axis length of approximate ellipse). For a perfectly round gap, the major and minor axes are of equal lengths and roundness equals 1 , but the more the major axis increases relative to the minor axis, the more declines the roundness towards 0 . Based on the area and perimeter, we also calculated the gap shape complexity index: GSCI $=\frac{P}{\sqrt{4 \pi A}}$, which is the ratio of a gap's perimeter to the perimeter of a circular gap of the same area (Koukoulas \& Blackburn 2004). A value of 1.0 describes a perfect circle and increasing values indicate increasing shape complexity. For instance, values of 1.4 and 2.6 have $40 \%$ and $160 \%$ complexity, respectively (Getzin et al. 2012). This GSCI is independent of the gap's area, hence small and large squares have the same index value of 1.128.

To differentiate between FCs and small gaps, we used a threshold area of $4 \mathrm{~m}^{2}$. This roughly approximates a diameter of $2 \mathrm{~m}$ used in previous studies as a lower threshold size to digitize FCs (Getzin et al. 2015, 2021a). In order to allow for potential shape complexities, especially of small gaps, we defined the threshold in terms of the number of pixels. Given an image resolution of $20 \mathrm{~cm} /$ pixel, small gaps classified as 1 to $<4 \mathrm{~m}^{2}$ could thus have a minimal number 25 pixels, while smallest FCs could have a minimal number of 400 pixels.

The LiDAR data (Fig. 1e) were processed in $R$ software (R Development Core Team 2019) using the package "lidr" following the process described in Roussel et al. (2020). Additionally, the packages "rgeos", "sf" and "raster" were used for management of the data. At first the raw data were thinned to 100 points $/ \mathrm{m}^{2}$ which reduces the original amount of data but also local variations in the point-cloud density due 
to the drone movement. The ground points classified by the drone system were used for the height normalization of the data. We used a spatial interpolation method based on a k-nearest neighbor algorithm ("knnidw") and inverse-distance weighting to determine the height of each point relative to the ground points (Roussel et al. 2020). Values with negative height values below the ground surface were then removed as noise points. From that thinned and normalized point cloud we then built a canopy-height model (CHM) based on a $0.25 \mathrm{~m}$ raster which describes the absolute height of the vegetation independent of potential variation in topography (Khosravipour et al. 2014; Getzin et al. 2017). The crowns of trees and shrubs were segmented using the algorithm "silva2016" derived from Silva et al. (2016). This method is based on a Voronoi tessellation approach to isolate each individual crown. For the identification of trees and shrubs we used a circular moving window with a diameter of $5 \mathrm{~m}$ to determine local maxima and minima. Shrubs were classified as such with local minima of $100 \mathrm{~cm}$, while trees had local minima of $300 \mathrm{~cm}$. Hence shrubs ranged in height between $100 \mathrm{~cm}$ to $<300 \mathrm{~cm}$.

Because the position of the local maxima was not centered in the segmented crowns, the center of mass was calculated for each shapefile of shrub and tree crown. This was done with the function "gCentroid" from the package "rgeos". These centers of mass were then analyzed with spatial statistics to determine the patterns of the woody vegetation.

Spatial statistical analysis

We used spatial statistical techniques to analyze the patterns of FCs, small gaps, trees, and shrubs. In this regard, the main interest was to investigate if the individual patterns and if pairs of patterns showed correlations. For univariate analyses of these four individual types of patterns, we used the pair-correlation function (short: $g_{11}$-function) and the null model complete spatial randomness (CSR) which is based on a homogeneous Poisson process. The neighborhooddensity function $g_{11}(r)$ describes significant deviation from a random pattern such as clustering or regularity at a given radius $r$, using a standardized density. It is the expected density of points at a given distance $r$ of an arbitrary point, divided by the intensity $\lambda$ of the pattern (Stoyan and Stoyan 1994). Under CSR, $g_{11}(r)=1$, aggregation is indicated by $g_{11}(r)>1$, while regularity has values of $g_{11}(r)<1$.

Additionally, we were particularly interested in assessing the spatial distribution of small gaps around FCs because it is assumed that both types of gaps emerge due to competition for water. Hence, there should be a consistent dependency of small gaps on the larger FCs which function as an extra source of water for the surrounding matrix vegetation (Getzin et al. 2021a). In order to analyze such patterns with two types of points we used the bivariate pair-correlation function $g_{12}(r)$ which is the expected density of points of pattern 2 at distance $r$ of an arbitrary point of pattern 1 , divided by the intensity $\lambda_{2}$ of pattern 2 . The FCs were treated as pattern 1 and the small gaps with a size of 1 to $<4 \mathrm{~m}^{2}$ were treated as pattern 2 . The toroidal shift null model was used for the bivariate analysis because it preserves the properties of the individual patterns and randomizes the relative locations between two patterns (Wiegand and Moloney 2004). The spatial correlation functions $g_{11}(r)$ and $g_{12}(r)$ were tested for significant deviations from the CSR null model using the fifth lowest and fifth highest values of 199 Monte Carlo simulations for constructing approximately 95\% simulation envelopes (Baddeley et al. 2014).

Finally, we applied bivariate nearest-neighbor analyses to investigate the distribution of the nearestneighbor distances of small gaps around the FCs. This measure allows for a straightforward interpretation of the distances of small gaps to their nearest FC. All spatial analyses were done in $R$-software (version 4.0.0) using the packages "spatstat" (Baddeley and Turner 2005).

\section{Results}

\section{Structural attributes}

The number of FCs in the $200 \mathrm{~m} \times 200 \mathrm{~m}$ study plots ranged between 305 and 477 , and the total area coverage between 8.2 and $16.2 \%$ (Table 1). Thereby, the youngest plot (FC-1) had the greatest cover with FCs and the largest FC sizes. The mean roundness of the FCs ranged from 0.63 in FC-L1 to 0.74 in FC-C5, and the gap shape complexity index, GSCI, from 1.34 in FC-C5 to 1.63 in FC-1. 
Generally, the number of small gaps was more variable than the number of FCs, with numbers ranging between 417 and 1134 . The total area coverage of small gaps was low, ranging between 1.7 and 5.2\%. Compared with the coverage of FCs in the plots FC-L1, FC-L2, FC-C5, and FC-1 the coverage of small gaps was 2.3, 2.9, 4.7, and 4.8 times lower, respectively, indicating overall a strong variability among the plots. The mean roundness of the small gaps was lower than that of the FCs and ranged between 0.58 in FC- 1 and 0.61 in FC-C5. The mean GSCI of small gaps ranged from 1.13 in FC-C5 to 1.17 in FC-1. In all four plots, the roundness and GSCI of the FCs were significantly greater than those of the small gaps at $p<0.001$ (two-tailed $t$-tests; Fig. 3).

Tree numbers were very variable in the four plots. Only 26 trees were identified in the relatively young plot FC-1, while 132 trees were found in the plot FC-
C5 (Table 1). Given that plot age after destructive fire refers to the succession of grasses but not to the fireresistant trees, unsurprisingly, the mean crown areas were quite similar in all four plots and ranged from 10.9 to $12.5 \mathrm{~m}^{2}$. With $42.98 \mathrm{~m}^{2}$ the largest crown area was found in FC-C5, and this was also the tallest found tree with a height of $6.67 \mathrm{~m}$. The total area coverage with tree crowns was very low in the plots, ranging between 0.7 and $3.6 \%$. The mean tree height ranged between 3.9 and $4.6 \mathrm{~m}$.

The number of shrubs was much higher than that of the trees, ranging between 91 and 259 individuals. Mean crown areas of shrubs were low, ranging from 1.3 to $2.1 \mathrm{~m}^{2}$. The total area coverage with shrubs was even lower than that of the trees. It ranged between 0.3 and $1.2 \%$.

Table 1 The structural attributes of the vegetation in the four study plots

\begin{tabular}{|c|c|c|c|c|}
\hline & FC-L1 & FC-L2 & FC-C5 & FC-1 \\
\hline \multicolumn{5}{|l|}{ Plot properties from RGB imagery } \\
\hline \# of FCs & 477 & 373 & 305 & 361 \\
\hline Min/mean/max area FCs $\left(\mathrm{m}^{2}\right)$ & $4.00 / 9.98 / 48.68$ & $4.00 / 12.84 / 33.88$ & $4.08 / 10.76 / 23.36$ & $4.00 / 17.98 / 138.84$ \\
\hline Total area coverage FCs $(\%)$ & 11.90 & 11.98 & 8.20 & 16.23 \\
\hline Min/mean/max roundness FCs & $0.20 / 0.63 / 0.99$ & $0.25 / 0.70 / 0.98$ & $0.27 / 0.74 / 0.99$ & $0.23 / 0.69 / 0.98$ \\
\hline Min/mean/max GSCI FCs & $1.07 / 1.49 / 3.00$ & $1.08 / 1.46 / 2.39$ & $1.07 / 1.34 / 2.27$ & $1.09 / 1.63 / 3.95$ \\
\hline \# of small gaps & 1134 & 956 & 417 & 783 \\
\hline Min/mean/max area small gaps $\left(\mathrm{m}^{2}\right)$ & $1.00 / 1.84 / 3.96$ & $1.00 / 1.74 / 3.96$ & $1.00 / 1.67 / 3.96$ & $1.00 / 1.73 / 3.96$ \\
\hline Total area coverage small gaps $(\%)$ & 5.21 & 4.16 & 1.74 & 3.38 \\
\hline Min/mean/max roundness small gaps & $0.21 / 0.59 / 1.00$ & $0.23 / 0.59 / 1.00$ & $0.22 / 0.61 / 0.99$ & $0.24 / 0.58 / 1.00$ \\
\hline Min/mean/max GSCI small gaps & $1.00 / 1.16 / 1.78$ & $1.00 / 1.15 / 1.70$ & $1.00 / 1.13 / 1.79$ & $1.00 / 1.17 / 1.71$ \\
\hline \multicolumn{5}{|l|}{ Plot properties from LiDAR } \\
\hline \# of trees & 38 & 60 & 132 & 26 \\
\hline Min/mean/max area trees $\left(\mathrm{m}^{2}\right)$ & $1.23 / 12.54 / 24.53$ & $0.65 / 11.51 / 26.10$ & $1.66 / 10.86 / 42.98$ & $2.85 / 11.26 / 28.34$ \\
\hline Total area coverage of trees $(\%)$ & 1.19 & 1.73 & 3.58 & 0.73 \\
\hline Min/mean/max height trees (m) & $3.09 / 3.94 / 5.18$ & $3.05 / 4.08 / 5.91$ & $3.00 / 4.09 / 6.67$ & $3.23 / 4.55 / 6.03$ \\
\hline \# of shrubs & 259 & 135 & 197 & 91 \\
\hline Min/mean/max area shrubs $\left(\mathrm{m}^{2}\right)$ & $0.21 / 1.88 / 7.89$ & $0.25 / 1.79 / 10.01$ & $0.23 / 2.11 / 8.55$ & $0.26 / 1.30 / 9.05$ \\
\hline Total area coverage of shrubs $(\%)$ & 1.22 & 0.60 & 1.04 & 0.30 \\
\hline Min/mean/max height shrubs (m) & $1.00 / 1.68 / 2.95$ & $1.01 / 1.74 / 2.93$ & $1.00 / 1.95 / 2.96$ & $1.02 / 1.81 / 2.97$ \\
\hline
\end{tabular}

The plot properties from drone-based RGB imagery describe the size and shape characteristics of the FCs and small gaps. The plot properties derived from drone-based LiDAR show the structural attributes of the woody vegetation such as trees and shrubs

FC fairy circle, GSCI gap shape complexity index 
(a)

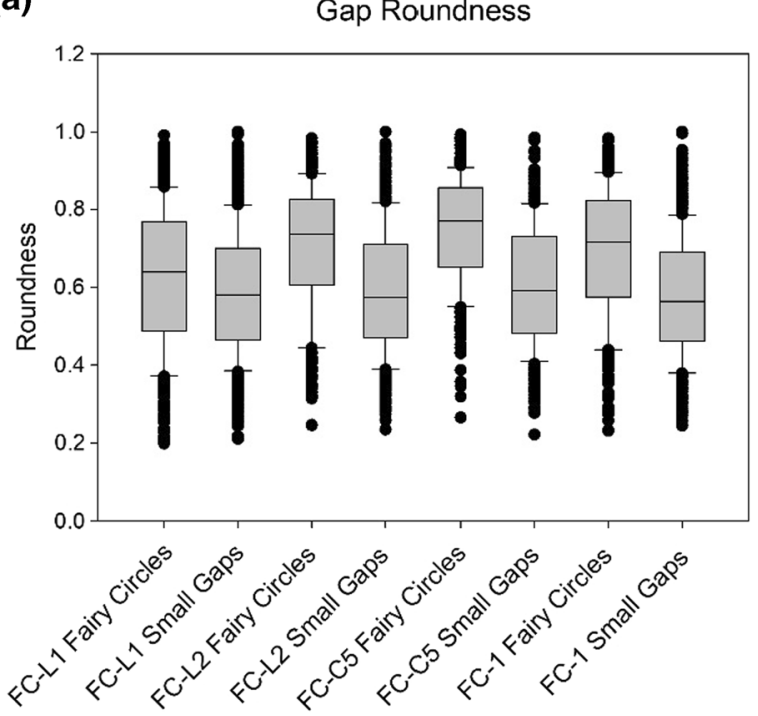

Fig. 3 Shape properties of the vegetation gaps. The roundness (a) and gap shape complexity (b) of the FCs were in all four plots significantly greater than for the small gaps. The black

Spatial statistical results

For the plot FC-L1, which had vegetation patterns with transitions from FCs to labyrinthine gap patterns, univariate analysis of the FCs with the $g_{11}$-function did not show a spatially periodic ordering but merely a regular pattern (Fig. 4a). For the plots FC-L2, FC-C5, and FC-1 the $g_{11}$-functions of the FCs showed a spatially periodic behavior with significant fluctuations around the null-model envelopes (Fig. 4b-d).

The small vegetation gaps in the plots showed a consistent pattern with strong regularity at the smallest scales and a positive peak shortly at the scales thereafter in all plots (Fig. 4e-h). At larger scales, the $g_{11}$-functions deviated in the plots FC-L2, FC-C5, and FC-1 from the homogeneous Poisson process of the CSR null model, indicating a heterogeneous distribution with varying densities. This was in contrast to the FCs, which were large-scale homogeneously distributed (i.e. inside the CSR null-model envelopes at large scales $r$, Fig. 4a-d).

The bivariate $g_{12}$-functions showed a consistent pattern for all four plots. At smallest neighborhood scales, no small gaps were found around the FCs, which is expected because otherwise the FCs and small gaps could not be separate entities. But consistently at around $5 \mathrm{~m}$ distance away from the FC (b)

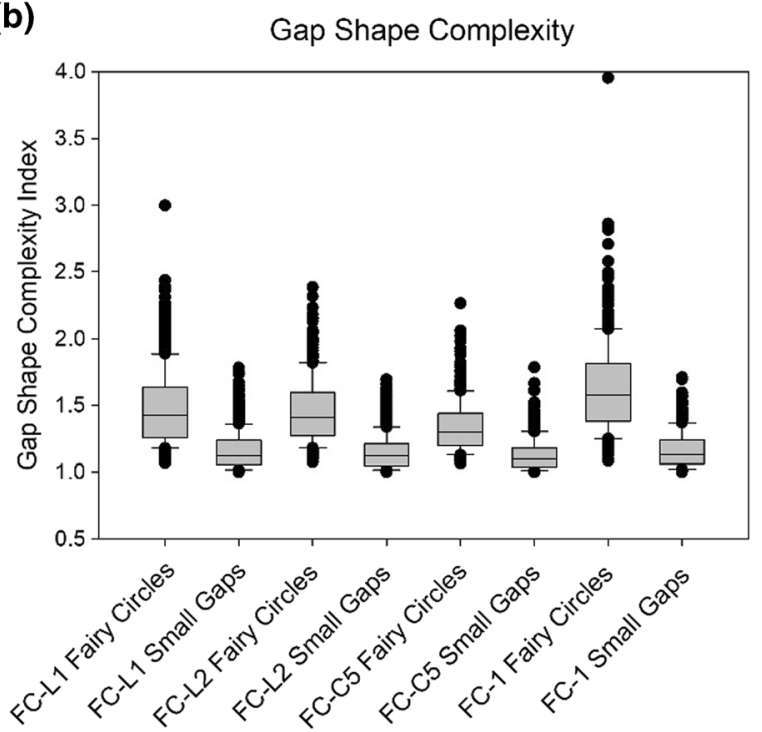

horizontal lines indicate the median. Significance was assessed via two-tailed $t$-tests and $p<0.001$

centers, small gaps strongly clustered and the $g_{12^{-}}$ function showed its highest positive peak (Fig. 4i-1). Hence, irrespective of the density and large-scale spatial distribution of small gaps within a study plot, their spatial relation to the FCs was always the same.

Also, the bivariate nearest-neighbor distributions of small gaps around the FCs reveal the consistent distances of small gaps towards nearby FCs (Fig. 5). The mean nearest-neighbor distances of small gaps towards FCs in the plots FC-L1, FC-L2, FC-C5, and FC-1 were $4.9 \mathrm{~m}, 5.1 \mathrm{~m}, 5.4 \mathrm{~m}$, and $5.0 \mathrm{~m}$, respectively.

Finally, the pattern analysis of trees and shrubs showed a strong mismatch with the univariate pattern of the FCs and even those of small gaps. Unlike those two types of grassland gaps, the trees showed for smallest scales a tendency to clustering, which however was only significant for the plot FC-1 (Fig. 6a-d). The shrubs showed primarily a tendency to random patterns at small scales and only the shrubs in plot FCL1 had a strongly regular small-scale pattern with $g_{11}(r)=0$ (Fig. 6e-h). 
FC-L1:

FCs \& Small Gaps

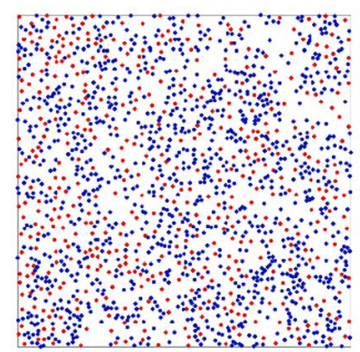

(a)

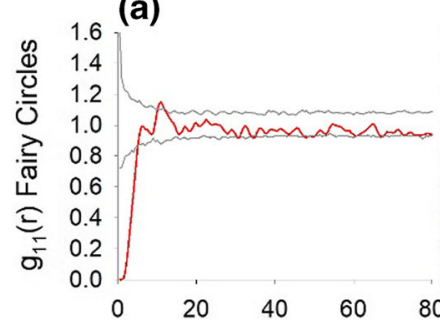

(e)
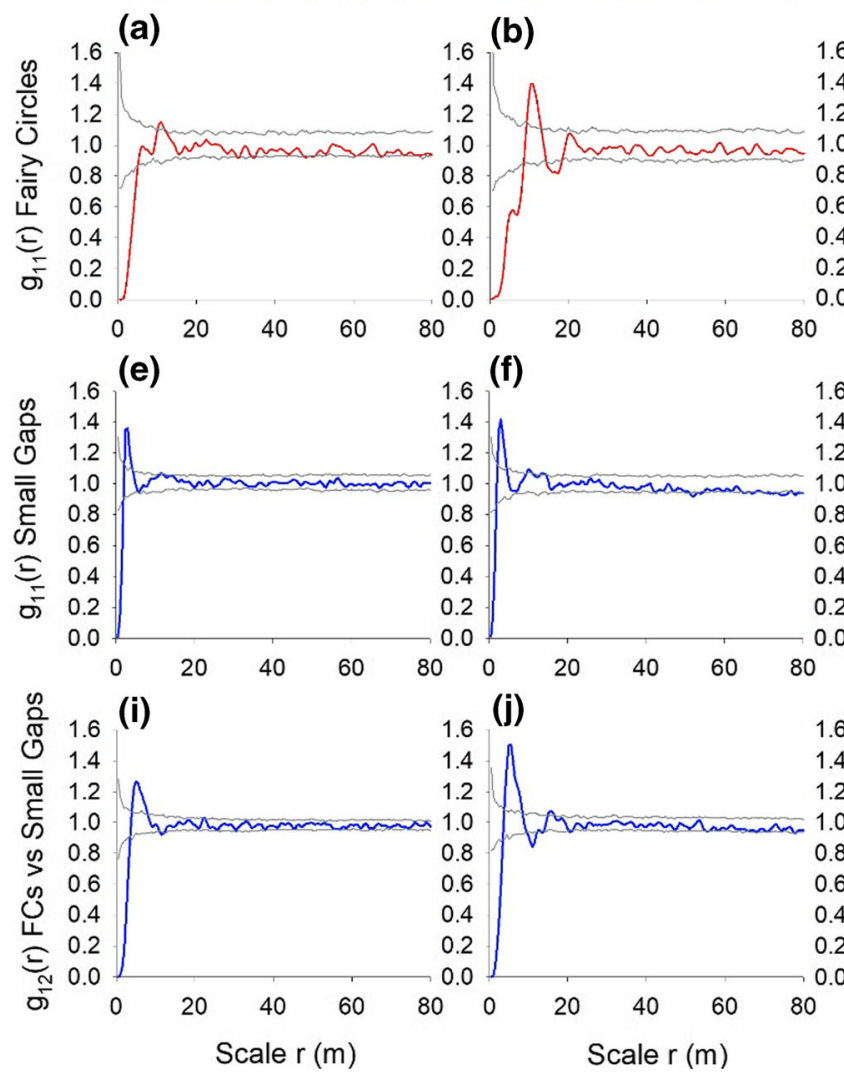

Fig. 4 Spatial patterns of FCs (red dots) and small gaps (blue dots) in the $200 \mathrm{~m} \times 200 \mathrm{~m}$ study plots. Univariate paircorrelation functions for the FCs $(\mathbf{a}-\mathbf{d})$. The same univariate analyses for the small gaps $(\mathbf{e}-\mathbf{h})$. Bivariate pair-correlation functions for the FCs and small gaps to assess the scaledependent density of small gaps around FCs $(\mathbf{i}-\mathbf{l})$. In univariate analyses, the pattern is regular and aggregated at scale $r$ if the red line of $g_{11}(r)$ is below the lower and above the upper gray

\section{Discussion}

With this study, we aimed at quantifying the vegetation structure in a wooded spinifex grassland of Western Australia, using high-resolution images and
FC-C5:

FCs \& Small Gaps

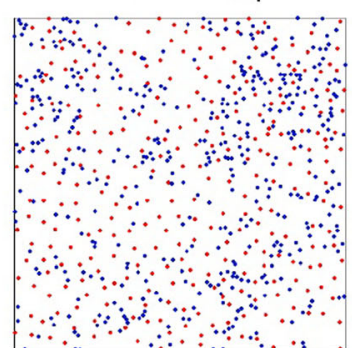

(c)
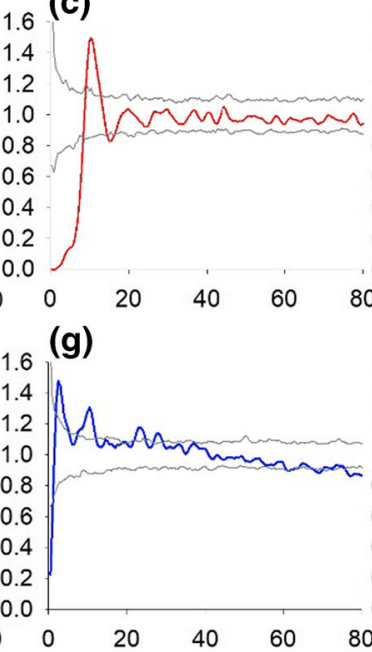

(k)

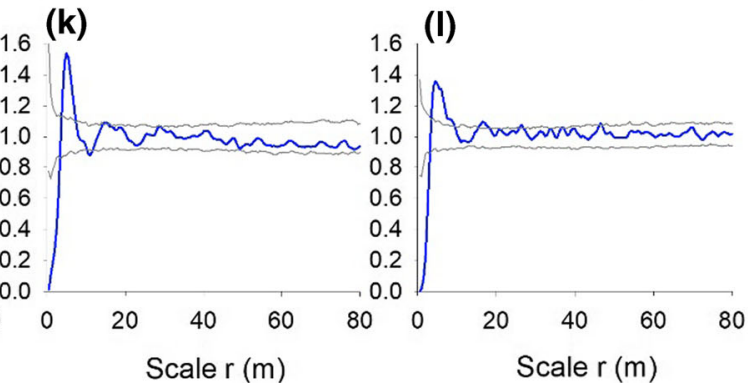

simulation envelopes, respectively. In bivariate analyses, small gaps are segregated from and aggregating around FCs at scale $r$ if the blue line of $g_{12}(r)$ is below the lower and above the upper gray simulation envelopes, respectively. Approximately $95 \%$ simulation envelopes were constructed using the 5th-lowest and 5th-highest value of 199 Monte Carlo simulations of the CSR null model

drone-based LiDAR. The primary focus of the study was on the spatial properties of the grassland gaps and how small, potentially newly forming gaps appear relative to the FCs which dominate this arid ecosystem. Our approach of employing an automatic 
FC-L1:

Small Gaps to FCs

(a)

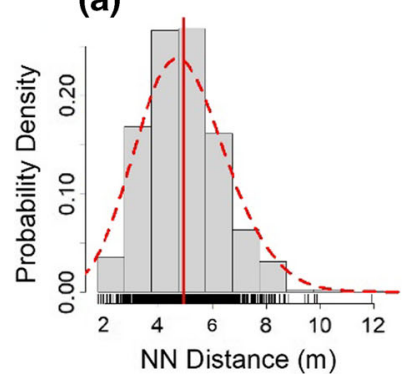

FC-L2: Small Gaps to FCs

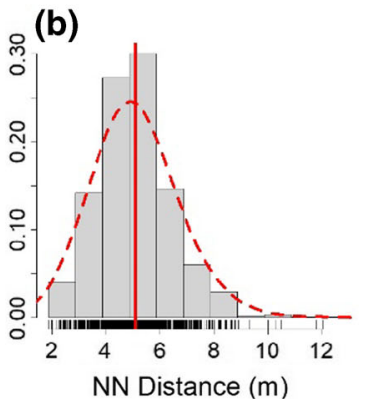

FC-C5:

Small Gaps to FCs

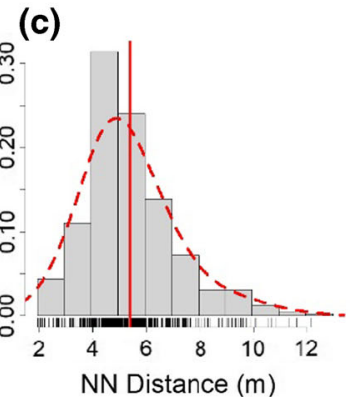

FC-1:

Small Gaps to FCs

(d)

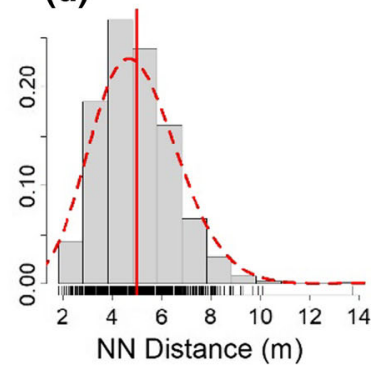

Fig. 5 Bivariate nearest-neighbor $(\mathrm{NN})$ distributions of the small gaps, relative to the nearest fairy circles (FCs). The red vertical lines show the mean nearest-neighbor distances of small gaps to the FCs

segmentation of gaps enabled us to assess in an objective manner even the most complex shapes of vegetation structure. This applies also to the dronebased LiDAR analysis of the woody plant components.

\section{Automatic segmentation of FCs and small gaps}

The automatic segmentation of FCs, using conversion into binary images and analysis with ImageJ software, resulted in structural attributes and spatial patterns that strongly agreed with manual segmentation work of the same FC plots. For example, previous manual FC segmentation of the $200 \mathrm{~m} \times 200 \mathrm{~m}$ plot FC-C5 resulted in $312 \mathrm{FCs}$ or equivalently in $78 \mathrm{FCs}$ per hectare (Getzin et al. 2016). Here we found 305 FCs for the same plot. Also, the largest FCs in the plots FCL1, FC-L2, and FC-C5 were 48.7, 33.9, and $23.4 \mathrm{~m}^{2}$ in area respectively, equaling previously reported maximal diameters of six to above seven meters (Getzin et al. 2016). There was only the one plot FC-1, where the five largest segmented FCs appeared too large with sizes of 50.8, 53.1, 61.4, 62.2, and $138.8 \mathrm{~m}^{2}$. This plot had an estimated post-fire age of about 10 years and hence it was the youngest of all. The grass vegetation was thus not yet in the full climax stage as in the other three older plots, as can be seen on the large fragmented bare-soil areas in FC-1, especially in the southern part of the plot (Fig. 2d). This lower density and biomass of the perennial grass species Triodia basedowii in FC-1 is also indicated by the highest total area coverage of FCs, which was with $16.2 \%$, about twice as high as in the FC-C5 plot. Additionally, the mean gap shape complexity index and the maximal
GSCI of FCs were found in the plot FC-1 to be highest, which results from more fragmented gaps due to lower grass density at the circular periphery of the FC. The original plot name "C5" denotes that this site was dominated by "purely gapped FC patterns" and thus circles, while the "L" in L1 and L2 indicates that these plots of the same climax stage were "partly interspersed with labyrinthine vegetation patterns" (cf. Getzin et al. 2016). It is therefore not surprising that the roundness of the FCs in FC-C5 was highest and the shape complexity was lowest (Table 1).

Despite slight effects from labyrinthine vegetation patterns in the plot FC-L2 or from larger bare-soil coverage due to younger vegetation in FC-1, the paircorrelation or $g$-functions showed a spatially periodic ordering of FCs for all plots, except for FC-L1 which had strong labyrinthine effects. Usually, it is necessary to analyze larger observation windows such as $500 \mathrm{~m} \times 500 \mathrm{~m}$ to reveal spatial periodicity of the FCs (Getzin et al. 2016, 2019a). Therefore, the second negative peak of the $g$-function is not as strongly deviating from the lower simulation envelope of the null model, as would be obtained with larger plot sizes (Getzin et al. 2019a,b). However, given that the FC features and the centers of mass were automatically extracted and that FC shapes were in part strongly fragmented such as in FC-1, the resultant $g$-functions reveal sufficiently well the typical, spatially periodic ordering of the FCs. Only in the plot FC-L1, the FCs did not show spatially periodic ordering because of the additional effects from labyrinthine vegetation-gap transitions. 

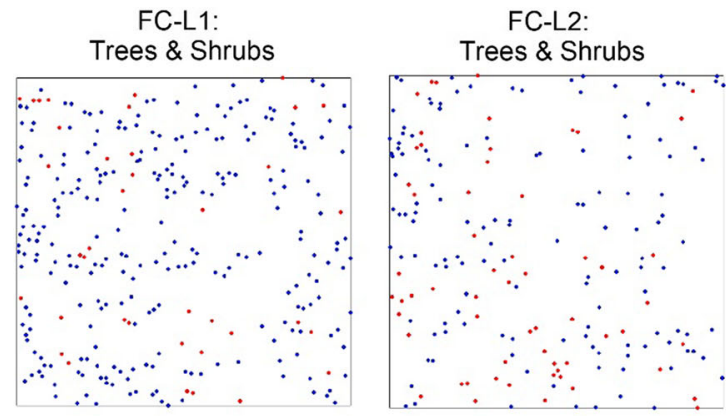

(b)
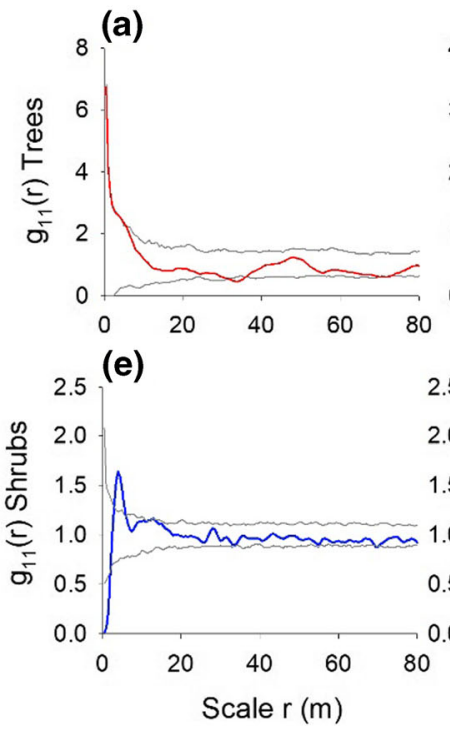

Fig. 6 Spatial patterns of trees (red dots) and shrubs (blue dots) in the $200 \mathrm{~m} \times 200 \mathrm{~m}$ study plots. Univariate pair-correlation functions for the trees (a-d). The same univariate analyses for the shrubs $(\mathbf{e}-\mathbf{h})$. For details see Fig. 4

Ecological interpretation of spatial patterns

Neither the small gaps with sizes of 1 to $<4 \mathrm{~m}^{2}$, nor the woody vegetation structure have so far been analyzed as individual patterns for the Triodia grasslands with FCs. For this reason, we formulated the three hypotheses as listed in the Introduction.

The first hypothesis suggests that small gaps should occur segregated from the larger FCs which supply the surrounding matrix vegetation with water. This is because the Australian FCs are self-organized vegetation gaps that result from scale-dependent competition for water (Getzin et al. 2016, 2021a). Hence, also the small gaps in the matrix should be an expression for a shortage of water at "fixed" distances away from the FCs. Our study confirms this hypothesis. Indeed, the strong consistency and geometric ordering of the distribution of small gaps, relative to the position of
FCs, is the most striking result of our study. Nevertheless, the number of small gaps per plot was very variable, ranging between 417 and 1134. Also, the density of small gaps across the plots was variable, as is visible from the maps of the plots and from the $g_{11^{-}}$ functions that tended to deviate from a homogeneous Poisson process for larger scales, most noticeably for the plots FC-C5 and FC-1 (Fig. 4 g,h). While these study plots are generally very flat and homogeneous, the variability in the density of small gaps could be attributed to differences in micro-topography or in soil texture, that we generally classify as environmental noise. Moreover, the aggregations of trees and shrubs in certain areas of the plots, such as particularly in FCC5 (Fig. 2c), may lower the likelihood to find small gaps in these patches. Another reason for variable densities of small gaps across the plots may be patchy fire activity where certain areas in a plot have burnt 
less strongly than other areas, e.g. due to changing wind conditions (Haydon et al. 2000). This becomes visible in the plot FC-1 where varying levels of greenness indicate spatial fluctuations in past fire activity (Fig. 2d).

Nevertheless, despite the environmental noise, the bivariate $g_{12}$-functions and also the bivariate nearestneighbor distributions were nearly identical. More precisely, the consistent mean nearest-neighbor distance of about $5 \mathrm{~m}$ indicates that the small gaps are not just a random event in space, but they have a systematic relation to the FCs. Given that the FCs function as an extra source of water for the surrounding grass vegetation and that the mean nearestneighbor distance between the FCs is about $10 \mathrm{~m}$ (Getzin et al. 2016), the dominant appearance of the small gaps at $5 \mathrm{~m}$ radius is precisely the distance which is furthest away from the FCs.

These findings demonstrate that the emergence of bare-soil gaps follows rules of periodically patterned dryland vegetation where the wavelength of the baresoil distances results from negative long-range feedbacks under a given aridity stress (Meron 2012). Related gapped patterns resulting from plant selforganization are also known from Niger (Barbier et al. 2008) or Sudan (Deblauwe et al. 2011), and banded patterns have been documented for Mexico (Deblauwe et al. 2011) or the Australian Outback (Ludwig et al. 2005, Okin et al. 2015).

Our new results also support our second hypothesis. If the spatially periodic pattern of the FCs results from symmetric competition for water in this flat and homogeneous landscape, then this competition should be equally strong across the plots. Consequently, the long-lived FCs should be rounder than the small new gaps. This was confirmed for all four research plots. Additionally, the highest mean roundness was found in the most typical FC plot FC-C5, while the younger 10-year-old plot (FC-1) had less round FCs. This demonstrates that over time, plants arrange themselves in an increasingly round formation around the FC water source which is a more efficient pattern of benefiting from the overland water flow from the gap centers towards the FC edges. The function of the FCs as an additional source of water for the surrounding grasses becomes thereby increasingly symmetrical. The fact that the GSCI, a shape index that is independent of the gap area, was higher for the FCs than for the small gaps indicates that these round large circles are not fully closed but there are always openings where water can flow through towards the matrix, thereby enabling a functional connectivity of resource flow within the arid landscape (Okin et al. 2015). This openness which leads to a certain fragmentation and also to partly labyrinthine transitions has been interpreted as a dynamic adaption of the grasses to the large-scale distribution of water in the plots, which may even result in partial revegetation of FCs with some individual grass hummocks (Getzin et al. 2019b). Such changes of FC sizes and forms are particularly known from Namibia, where the annual plants react more dynamically to the stochastic rainfall cycles (Zelnik et al. 2015).

Finally, we hypothesized that trees and shrubs with their longer roots should compete primarily for water in the deeper sub-soil layers, while grasses compete for water in the top-soil layer (Ward et al. 2013). Their spatial patterns should therefore be unrelated to the FC patterns. This was also confirmed by our LiDAR mapping of trees and shrubs and subsequent spatial analysis of the patterns. For small scales, the trees showed a tendency to clustering and the shrubs a tendency to random patterns. Such patterns strongly differ from the small-scale ordering of the FCs, hence a hypothetical link between the death of trees and resultant formation of a FC (whatever the mechanism shall be in that case) can be rejected. The clustering of the trees is indicative for facilitative processes (Holmgren et al. 1997) whereby shading induced by the crowns enables the survival of several species in the immediate neighborhood (Fig. 1c, e, S2). These spatial results are very similar to Namibia where the pattern of Euphorbia shrubs was predominantly clustered or random, and therefore the shrubs cannot explain the periodic regularity of the Namibian FCs (Getzin et al. 2021b). Our analysis of the vegetation structure also reveals that the total area of tree and shrub coverage in the plots was very low and that especially the number of trees was very variable with the plot FC-C5 having five times more trees than FC-1. From these numbers we conclude that the woody components only have a random effect on the grassland system with regard to the spatially periodic pattern of fairy circles. Thus, woody plants are not a key driver of the vegetation gap structure in this Australian FC landscape. 


\section{Conclusions}

The main goal of the study was to investigate the pattern characteristics of small gaps and larger FCs. We were able to show that small gaps consistently formed at those locations which were furthest away from their nearest-neighboring FCs. Although mathematically this was to be somewhat expected (Meron 2012), empirically this is a remarkable result given the environmental noise and the high spatial variability of the small gaps in these four study areas. The consistency in the patterning of small gaps, relative to the neighboring FCs, is an expression for the lack of water at those locations that are about five meters away from the FCs, which function as an extra source of water for the matrix vegetation. Also, we could finally demonstrate that the trees and shrubs with their different spatial patterns, as well as with their low area coverage and variable numbers, are only random components in this grassland ecosystem that seem to not affect the dynamics and the formation of the periodic FC patterns. In support of our previous studies, here we highlight that the Australian FCs are a prime example of vegetation self-organization which is driven by ecohydrological feedbacks and plant competition for water.

Acknowledgements We are grateful to the CASA/Aviation Group for permitting us to undertake the drone flights. We thank the drone company Microdrones in Germany for their technical support. BHP Western Australia Iron Ore, Rio Tinto and Barry Gratte from Ethel Creek Company are thanked for their permissions to undertake fieldwork on their land. Bronwyn Bell and Lawrence Billson are thanked for their help in Perth and Emma Stock for assistance in the Pilbara. This study was supported by the German Research Foundation (DFG), Grant Number 323093723.

Author contributions SG and TEE conceptualized the study; SG, TEE, HY and MM-R collected the data; SG, CL, and TEE analysed the data; SG, TEE, HY, MM-R, AH and KW wrote the paper.

Funding Open Access funding enabled and organized by Projekt DEAL. This study was supported by the German Research Foundation (DFG), Grant Number 323093723.

Data availability Data on the spatial positions of objects can be obtained from the first authors. Raw data such as drone images and laser scans are confidential, as they are subject to ongoing publications.

Code availability Not applicable.
Declarations

Conflict of interest The authors declare no conflicts or competing of interests.

Ethical approval Not applicable.

Consent to participate All authors declare to consent to participate of this study.

Consent for publication All authors declare to consent the publication of this study.

Open Access This article is licensed under a Creative Commons Attribution 4.0 International License, which permits use, sharing, adaptation, distribution and reproduction in any medium or format, as long as you give appropriate credit to the original author(s) and the source, provide a link to the Creative Commons licence, and indicate if changes were made. The images or other third party material in this article are included in the article's Creative Commons licence, unless indicated otherwise in a credit line to the material. If material is not included in the article's Creative Commons licence and your intended use is not permitted by statutory regulation or exceeds the permitted use, you will need to obtain permission directly from the copyright holder. To view a copy of this licence, visit http://creativecommons.org/licenses/by/4.0/.

\section{References}

Abensperg-Traun M, Perry DH (1998) Distribution and characteristics of mound-building termites (Isoptera) in Western Australia. J R Soc West Aust 81:191-200

Baddeley A, Turner R (2005) Spatstat: an R package for analyzing spatial point patterns. J Stat Softw 12:1-42

Baddeley A, Diggle PJ, Hardegen A, Lawrence T, Milne RK, Nair G (2014) On tests of spatial pattern based on simulation envelopes. Ecol Monogr 84:477-489

Barbier N, Couteron P, Lefever R, Deblauwe V, Lejeune O (2008) Spatial decoupling of facilitation and competition at the origin of gapped vegetation patterns. Ecology 89:1521-1531

Deblauwe V, Barbier N, Couteron P, Lejeune O, Bogaert J (2008) The global biogeography of semiarid periodic vegetation patterns. Glob Ecol Biogeogr 17:715-723

Deblauwe V, Couteron P, Lejeune O, Bogaert J, Barbier N (2011) Environmental modulation of self-organized periodic vegetation patterns in Sudan. Ecography 34:990-1001

Dibner RR, Doak DF, Lombardi EM (2015) An ecological engineer maintains consistent spatial patterning, with implications for community-wide effects. Ecosphere 6:151

Caviedes-Voullième D, Hinz C (2020) From nonequilibrium initial conditions to steady dryland vegetation patterns: how trajectories matter. Ecohydrology 13:e2199

Fernandez-Oto C, Tlidi M, Escaff D, Clerc MG (2014) Strong interaction between plants induces circular barren patches: fairy circles. Phil Trans R Soc A 372:20140009 
Getzin S, Yizhaq H (2019) Unusual Namibian fairy circle patterns in heterogeneous and atypical environments. J Arid Environ 164:85-89

Getzin S, Wiegand K, Schoening I (2012) Assessing biodiversity in forests using very high-resolution images and unmanned aerial vehicles. Methods Ecol Evol 3:397-404

Getzin S, Wiegand K, Wiegand T, Yizhaq H, von Hardenberg J, Meron E (2015) Adopting a spatially explicit perspective to study the mysterious fairy circles of Namibia. Ecography 38:1-11

Getzin S, Yizhaq H, Bell B, Erickson TE, Postle AC, Katra I, Tzuk O, Zelnik YR, Wiegand K, Wiegand T, Meron E (2016) Discovery of fairy circles in Australia supports selforganization theory. Proc Natl Acad Sci 113:3551-3556

Getzin S, Fischer R, Knapp N, Huth A (2017) Using airborne LiDAR to assess spatial heterogeneity in forest structure on Mount Kilimanjaro. Landsc Ecol 32:1881-1894

Getzin S, Yizhaq H, Cramer MD, Tschinkel WR (2019a) Contrasting global patterns of spatially periodic fairy circles and regular insect nests in drylands. J Geophys Res 124:3327-3342

Getzin S, Yizhaq H, Muñoz-Rojas M, Wiegand K, Erickson TE (2019b) A multi-scale study of Australian fairy circles using soil excavations and drone-based image analysis. Ecosphere 10:e02620

Getzin S, Erickson TE, Yizhaq H, Muñoz-Rojas M, Huth A, Wiegand K (2021a) Bridging ecology and physics: Australian fairy circles regenerate following model assumptions on ecohydrological feedbacks. J Ecol 109:399-416

Getzin S, Nambwandja A, Holch S, Wiegand K (2021b) Revisiting Theron's hypothesis on the origin of fairy circles after four decades: Euphorbias are not the cause. BMC Ecology Evolution 21:102

Haydon DT, Friar JK, Pianka ER (2000) Fire-driven dynamic mosaics in the Great Victoria Desert, Australia - I. Fire geometry. Landsc Ecol 15:373-381

Holmgren M, Scheffer M, Huston MA (1997) The interplay of facilitation and competition in plant communities. Ecology 78:1966-1975

Isbell RF (2002) The Australian soil classification. Rev. Edition. CSIRO Publications, Collingwood

Khosravipour A, Skidmore AK, Isenburg M, Wang T, Hussin YA (2014) Generating pit-free canopy height models from airborne lidar. Photogram Eng Remote Sens 80:863-872

Koukoulas S, Blackburn GA (2004) Quantifying the spatial properties of forest canopy gaps using LiDAR imagery and GIS. Int J Remote Sens 25:3049-3071

Levin N, Levental S, Morag H (2012) The effect of wildfires on vegetation cover and dune activity in Australia's desert dunes: a multisensor analysis. Int $\mathrm{J}$ Wildland Fire 21:459-475

Ludwig JA, Wilcox BP, Breshears DD, Tongway DJ, Imeson AC (2005) Vegetation patches and runoff-erosion as interacting ecohydrological processes in semiarid landscapes. Ecology 86:288-297

Maestre FT, Benito B, Berdugo M, Concostrina-Zubiri L, Delgado-Baquerizo M, Eldridge DJ et al (2021) Biogeography of global drylands. New Phytol 231:540-558

Meron E (2012) Pattern-formation approach to modelling spatially extended ecosystems. Ecol Model 234:70-82
Muñoz-Rojas M, Erickson TE, Martini D, Dixon KW, Merritt DJ (2016) Soil physicochemical and microbiological indicators of short, medium and long term post-fire recovery in semi-arid ecosystems. Ecol Ind 63:14-22

Newman EA, Kennedy MC, Falk DA, McKenzie D (2019) Scaling and complexity in landscape ecology. Front Ecol Evol 7:293

Nicolai N, Feagin RA, Smeins FE (2010) Spatial patterns of grass seedling recruitment imply predation and facilitation by harvester ants. Environ Entomol 39:127-133

Noble J, Diggle P, Whitford W (1989) The spatial distributions of termite pavements and hummock feeding sites in a semiarid woodland in eastern Australia. Acta Oecol-Oec Gen 10:355-376

Okin GS, Heras MM, Saco PM, Throop HL, Vivoni ER, Parsons AJ, Wainwright J, Peters DPC (2015) Connectivity in dryland landscapes: shifting concepts of spatial interactions. Front Ecol Environ 13:20-27

R Development Core Team (2019) R: a language and environment for statistical computing. R Foundation for Statistical Computing, Vienna

Ravi S, D'Odorico P, Wang L, Collins S (2008) Form and function of grass ring patterns in arid grasslands: the role of abiotic controls. Oecologia 158:545-555

Ravi S, Wang L, Kaseke KF, Buynevich IV, Marais E (2017) Ecohydrological interactions within "fairy circles" in the Namib Desert: revisiting the self-organization hypothesis. J Geophys Res 122:405-414

Ross ND, Moles AT (2021) The contribution of pathogenic soil microbes to ring formation in an iconic Australian arid grass, Triodia basedowii (Poaceae). Aust J Bot 69:113-120

Roussel J-R, Auty D, Coops NC, Tompalski P, Goodbody TR, Meador AS, Bourdon J-F, de Boissieu F, Achim A (2020) lidR: An R package for analysis of Airborne Laser Scanning (ALS) data. Remote Sens Environ 251:112061

Silva CA, Hudak AT, Vierling LA, Loudermilk EL, O'Brien JJ, Hiers JK, Jack SB, Gonzalez-Benecke C, Lee H, Falkowski MJ, Khosravipour A (2016) Imputation of individual longleaf pine (Pinus palustris Mill.) tree attributes from field and LiDAR data. Can J Remote Sens 42:554-573

Stoyan D, Stoyan H (1994) Fractals, random shapes and point fields. Methods of geometrical statistics. Wiley

Tschinkel WR (2010) The foraging tunnel system of the Namibian desert termite, Baucaliotermes hainesi. J Insect Sci 10:1-17

Tschinkel WR (2012) The life cycle and life span of Namibian fairy circles. PLoS ONE 7:e38056

Turner J, Marais E, Vinte M, Mudengi A, Park W (2006) Termites, water and soils. Agricola 16:40-45

van Rooyen MW, Theron GK, van Rooyen N, Jankowitz WJ, Matthews WS (2004) Mysterious circles in the Namib Desert: review of hypotheses on their origin. J Arid Environ 57:467-485

van Vreeswyk AM, Leighton KA, Payne AL, Hennig P (2004) An inventory and condition survey of the Pilbara region, Western Australia. Department of Agriculture and Food, Western Australia, Perth. Technical Bulletin 92

Wallace L, Lucieer A, Malenovský Z, Turner D, Vopěnka P (2016) Assessment of forest structure using two UAV techniques: a comparison of airborne laser scanning and structure from motion (SfM) point clouds. Forests 7:62 
Ward D, Wiegand K, Getzin S (2013) Walter's two-layer hypothesis revisited: back to the roots! Oecologia 172:617-630

Watson JAL, Lendon C, Low BS (1973) Termites in mulga lands. Trop Grassl 7:121-126

Wiegand T, Moloney KA (2004) Rings, circles, and nullmodels for point pattern analysis in ecology. Oikos 104:209-229
Zelnik YR, Meron E, Bel G (2015) Gradual regime shifts in fairy circles. Proc Natl Acad Sci 112:12327-12331

Publisher's Note Springer Nature remains neutral with regard to jurisdictional claims in published maps and institutional affiliations. 